\title{
Editorial 40
}

\author{
Eric R. Scerri
}

Published online: 31 March 2012

(c) Springer Science+Business Media B.V. 2012

This issue brings glad as well as sad tidings. The gladness comes from publishing some of the papers that were given at a very interesting conference on the philosophy of chemistry that was organized by Alan Chalmers in Sydney Australia. I will leave it to Alan to introduce the papers in the guest editorial that follows.

The sadness comes from having to announce the passing of as many as three scholars who were connected to our field to varying degrees, and two of whom authored articles in the journal. The first is Michael Laing to whom this issue is dedicated. I am sure that Michael would have loved to have been at the meeting in Sydney. Laing was a South African chemist and chemical educator with a highly original approach to foundational aspects of chemistry. Although he did not quite originate the notion, he was the leading advocate for the knight's move relationship in the periodic table, which connects together unexpected elements such as zinc and tin whose relative positions are similar to a knight's move in the game of chess. Michael was also the author of some outstanding articles on the periodic table (Laing 2005, 2007) in this journal as well as the guest editor on a special issue on the periodic system that included a contribution from Oliver Sacks (Scerri 2010).

The second recent loss has been that of Richard Bader, the internationally renowned theoretical chemist from MacMaster's University in Canada and the originator of many methods used routinely by chemists, including AIM or 'Atoms in Molecules'. Bader's critical, and often provocative, style is quite evident in a survey article on his work that he published in Foundations of Chemistry just a couple of months before his death (Bader 2011).

The third loss is that of Herb Kaesz, an inorganic chemist and much loved colleague of all of us who knew him at UCLA and all over the world. Among many accomplishments Herb prepared and studied the first carbonyl compounds of technetium soon after the metal became commercially available. He was also a member of various IUPAC committees, including the ones that presided over the naming of new elements such as seaborgium and all the fuss that accompanied this episode. Kaesz retained a deep interest in the periodic table as seen in an article he co-authored with Peter Atkins, for example (Kaesz and

E. R. Scerri $(\square)$

Department of Chemistry and Biochemistry, UCLA, Los Angeles, CA 90095, USA

e-mail: scerri@chem.ucla.edu 
Atkins 2003). In it they argued that the element hydrogen should be allowed to float majestically above the rest of the table. The debated position of hydrogen continues to exercise the minds of periodic table afficionados.

Having used a Spanish word in the context of the periodic table leads me naturally to announce the 3rd International Conference on the Periodic System which will be held in Cusco, Peru, in August. ${ }^{1}$ And to end on a further positive note, I should also mention the annual meeting of the International Society for the Philosophy of Chemistry that will take place in Leuven, Belgium, from August 7 to $10 .^{2}$

\section{References}

Bader, R.F.W.: On the non-existence of parallel universes in chemistry. Found. Chem. 13, 11-37 (2011) Kaesz, H., Atkins, P.: Chemistry International. 14 Nov-14 Dec 2003

Laing, M.: A revised periodic table: with the lanthanides repositioned. Found. Chem. 7, 203-233 (2005)

Laing, M.: Where to put hydrogen in a periodic table? Found. Chem. 9, 127-137 (2007)

Scerri, E.R.: Editorial 34. Found. Chem. 12, 1-3 (2010)

\footnotetext{
1 See announcement and call for papers in this issue.

2 See announcement and call for papers in this issue.
} 